\title{
La industria lechera en Ecuador: un modelo de desarrollo
}

Juan Pablo Grijalva Cobo*

Juan Pablo Grijalva Cobo, Presidente de la Asociación de Ganaderos de la Sierra y el Oriente (AGSO), realizó sus estudios en la Escuela Agrícola Panamericana en Honduras y en la Universidad de Massey de Nueva Zelandia.

Es productor agropecuario, dirigente gremial y empresarial, con amplia trayectoria en desarrollo de proyectos productivos; ha formado parte de varios directorios en organizaciones gremiales del Ecuador como la Cámara de Agricultura, Centros Agrícolas, asociaciones de carácter agropecuario en diferentes regiones del país y la Cámara de Industrias. Ha participado en negociaciones internacionales representando al sector privado ganadero.

Actualmente se desempeña como Gerente General de la AGSO, organización gremial con 46 años de vida institucional, que cuenta con aproximadamente 6.000 afiliados y tiene como objetivo el fomento de la producción pecuaria, para el abastecimiento alimentario del país y el mejoramiento del nivel de vida de la gente del campo. Es también Gerente General de la Sociedad Industrial Ganadera El Ordeño S.A. y además es miembro de la Junta Directiva de la Cámara de Industrias y Producción del Ecuador, entidad que agrupa a las principales industrias del Ecuador.

Ha diseñado y puesto en marcha un sinnúmero de proyectos productivos para favorecer la producción lechera y la incorporación de los pequeños productores a la economía nacional.

\section{JMG: ¿Cuáles son las nece- sidades de desarrollo de la ganadería en Ecuador?}

JPG: Actualmente, el conocimiento es de vital importancia para el desarrollo de cualquier actividad; también, el apoyo del Estado para retribuir los esfuerzos de los ganaderos nacionales con precios adecuados y apoyo en el crédito.

\section{¿Cuáles experiencias son efectivas para el desarrollo de la actividad ganadera?}

La mejor forma de trabajar con los productores de leche - tanto medianos como pequeños - ha sido convertirlos en socios estratégicos; es una alianza, pero no una obligación. Es justamente este principio de libertad el que la hace efectiva

\footnotetext{
Forma sugerida de citar: Grijalva Cobo, Juan Pablo. 2011. La industria lechera en Ecuador: un modelo de desarrollo. Retos 1. Enero/Junio. Pp. 65-70.
}

* Presidente de la Asociación de Ganaderos de la Sierra y el Oriente (AGSO). 
y nos diferencia de otros modelos de empresas comercializadoras, que les ponen la infraestructura y les obligan a vender su producción, sin asegurarles el precio justo. Nosotros les impulsamos a buscar las mejores alternativas, y ellos saben que es la nuestra, porque ha generado una gran confianza mutua.

\section{¿Cuáles han sido los mayores problemas que ha tenido que solucionar la AGSO?}

La mejora del autoestima ha sido el motor principal: el campesino ya no es un ente aislado, sino parte de un grupo organizado, con nombre y apellido, tiene una identidad. Recibe capacitación, aprende, tiene sed de conocimiento; puede que no sepa escribir bien y que no tenga algunas herramientas, pero tiene inteligencia y sentido común; si accede a la tecnología, se apropia y la combina con toda la práctica que tiene.

\section{¿Qué tipo de apoyo necesita de la universidad ecuatoriana para fortalecer la actividad lechera y qué vinculaciones está desarrollando la AGSO con el Laboratorio de la Leche de la UPS?}

Necesitamos que contribuya a la investigación en todas las áreas, documentar lo que hace la gente, los experimentos individuales de los productores: variedades de pastos, desarrollo genético, calidad de leche.
Tenemos programas de colaboración con la Universidad de las Américas y la Universidad del Pacífico, y el borrador de un convenio con otra universidad, pero lo ideal sería una coordinación entre todos estos programas. Nosotros no tenemos capacidad de investigación, pero sí acceso a organismos de financiamiento, necesitamos aliarnos con las universidades. Hasta ahora ha habido una separación absoluta entre las necesidades de la universidad y las nuestras.

\section{¿Cuál es la importancia de la actividad lechera en Ecuador; y se generan negocios entre pequeños empresarios y em- prendedores con la AGSO?}

Aproximadamente, se dedican 3,5 millones de hectáreas a la producción de leche; la mayor concentración está en la Sierra (75\%), la Amazonía (11\%) y la diferencia (14\%) en el resto del país. En la Sierra, la leche es el único producto de venta estable para el campesino, en las zonas altas no existen muchas opciones de siembra; entonces, la leche se convierte en lo que llamamos 'el sueldo del campo', porque recibe el fruto de su venta cada 15 días.

La estructura de la producción es interesante: existen 298 mil productores, la gran mayoría son medianos y pequeños; así que hablar de grandes productores es muy relativo. Por el tamaño, la mayoría 
de propiedades es de menos de 100 hectáreas, ahí se produce el 65\% de la leche - gran parte en la Sierra-; por otro lado, es una actividad que depende muchísimo de la población campesina, que es la que genera producción y empleo, especialmente de tipo familiar.

La AGSO, que conoce la realidad del campo y de la leche como única actividad de sustento de las familias y que, cuando las comunidades están desorganizadas, caen fácilmente en manos de intermediarios inescrupulosos, ha organizado centros de acopio y capacita a las comunidades para que puedan manejar por sí mismas las instalaciones. Lo que sirve para comercializar eficientemente y evita los mediadores que primero no les pagaban lo justo y, luego, no les daban la seguridad de compra y cuando había abundancia de leche era un desastre, no contaban con su sustento. Los centros de acopio organizan y logran que un pequeño productor pueda comercializar con otros mil.

\section{¿Qué tipo de acuerdo tienen los productores con la AGSO?}

Principalmente, es un acuerdo de caballeros que nos ha funcionado por mucho tiempo, que no necesita nada legal porque es un acuerdo de conveniencias; el famoso 'ganarganar'; funciona como una válvula de escape para proteger la estabilidad de los productores.

Retos I(I): 20I I.

(C) 20I I, Universidad Politécnica Salesiana del Ecuador

\section{¿Qué participación tuvo la AGSO en el desarrollo de la comunidad Pueblo Nuevo, en el noroccidente de Pichincha?}

La ayudamos a organizarse hace unos 20 años mediante el programa Queserías Rurales, con el Ministerio de Agricultura; funcionó tan bien que se independizaron y ahora son comunidades autogestionadas que aportan en gran medida al desarrollo del país.

\section{¿Cuánto ha contribuido la AGSO en la formación y capa- citación de los campesinos?}

Creo que bastantísimo, pero la tecnología que se les facilita no cambia lo que ellos conocen, pueden mejorar algunas prácticas y algunos procedimientos para volverlos más productivos, pero el cuidado de los animales viene en su genética, en su convivencia con ellos.

\section{¿Cuán importante es el com- ponente humano en la organi- zación?}

Es fundamental; al respecto tenemos un lema: Primero la gente, que se ha mantenido y funcionado por mucho tiempo. Las personas tienen un potencial gigantesco, que a veces está dormido, pero viene alguien y lo despierta. Hay ciertos líderes que ofrecen cosas y no las cumplen, y merman su capacidad de creer. Ahora, creen en ellos mismos y valoran lo que pueden ser y saben hacer. Cada uno de ellos es más empresario que nunca. 
¿Cuánto tiempo viene aplicando estos programas de desarrollo en el país?

En este programa específico, aproximadamente 10 años; en el trabajo comunitario, muchos. La AGSO tiene 47 años de vida y de apoyo fructífero a las comunidades lecheras del país.

\section{¿Cómo surgió la idea de estos programas de desarrollo?}

Es un modelo que lo hemos construido de forma conjunta; lo que se trajo de afuera fue el conocimiento de que la leche puede ser un vehículo estupendo de desarrollo. Vimos el caso de Nueva Zelanda, uno de los países con los niveles de vida más altos del mundo, que su éxito gira alrededor de la leche, tiene un gran impulso agropecuario, pero la leche representa un gran porcentaje del crecimiento de su economía. La leche es un polo de desarrollo muy importante, pero aquí, a pesar de las inmejorables condiciones que tenemos, aún no lo vemos así.

\section{¿La AGSO está creando pro- yectos o centros de capacita- ción de productos elaborados?}

En su estatuto social, la AGSO tiene un mandato que dice: "Promover la industrialización de la leche y sus subproductos". En obediencia a él promovió la empresa secadora de leche El Ordeño, que sostiene esta organización, y se va expandiendo a otras áreas.

Retos I(I): 201 I.

(C) 2011, Universidad Politécnica Salesiana del Ecuador
También fomenta la creación de empresas para industrializar lácteos; el lastre histórico que tiene al respecto Ecuador es que cuando la gente comienza a producir derivados, como el mercado no es estable, las empresas quiebran; lo que hacemos nosotros es comprar lo que no venden a precios normales y se seca y se hace polvo; entonces, los unos van al mercado como tales y el excedente, como leche en polvo.

\section{¿Qué pasaba con ese exce- dente?}

La leche se importaba principalmente para los programas de alimentación del gobierno; lo que hemos hecho es lograr que se sustituya por la producción nacional; ahora, además de ofrecer una alimentación balanceada, se les da trabajo; así formamos un triángulo perfecto y muy virtuoso.

Tratamos de que cada programa de gobierno esté anclado a pequeños productores en expansión, porque un productor pequeño puede subir su producción de 10 litros a 20 en poco tiempo, con un poco de tecnología y conocimiento.

\section{¿Qué es lo más importante en la formación profesional de una persona?}

Los valores humanos son fundamentales, es muy difícil que un profesional empiece a trabajar si no tiene esa mística; no hay que ofrecer un servicio para cobrar un valor de- 
terminado, hay que darlo para que haya un beneficio y que este tenga un valor; es un cambio total en la estructura mental de las personas.

\section{¿Qué vinculación ha desarro- Ilado la AGSO con el Labora- torio de Calidad de la Leche de la UPS en Cayambe?}

Hemos hecho análisis esporádicos, no bajo un programa serio, pero es algo que estamos trabajando para cambiar, hay una necesidad y voluntad totales de la AGSO para que el laboratorio funcione de forma continua y sea uno de los mejores a nivel nacional.

Un producto terminado nunca puede ser mejor que la leche original; es fundamental controlar su calidad desde el inicio, lo podemos asegurar por medio del análisis; por otro lado, necesitamos investigación que vaya de la mano con el laboratorio, necesitamos mejorar la composición de la leche, y encontrar las soluciones técnicas para ello.

\section{¿La leche en el país reúne los estándares de calidad reco- mendados?}

Reúne los estándares mínimos de calidad, de acuerdo a la norma INEN, pero nosotros tenemos que llegar a los estándares máximos, que tiene un impacto directo en la parte nutricional de la población y en la parte económica de los productores: si en el país se transportan 4,5 millones de litros de leche diarios, y esa leche tiene $11,9 \%$ de sólidos, si nosotros logramos subir a 12 ó $13 \%$ el impacto en el costo del transporte o del procesamiento será muy notable y, al final, redundará en el costo de la alimentación de los consumidores.

\section{¿Qué tipo de estudios econó- micos y administrativos nece- sita la AGSO?}

Modelos de gestión simples, hojitas que la gente pueda llenar y, a través de ellas, saber sus costos de producción, que establezcan una contabilidad básica que pueda ser manejada por los campesinos. Lo que queremos es que la tecnología se adapte a las personas y no al revés.

También queremos validar las variedades de pasto que estamos utilizando; cada día habrá más cambios climáticos, necesitamos encontrar variedades que puedan adaptarse a climas extremos, y para eso se necesita experimentación.

\section{¿Hay necesidad de desarrollar un programa a nivel nacional?}

Como parte del programa deberíamos hacer investigaciones de mercado, saber un poco qué es lo que los consumidores esperan de la leche, cómo se están consumiendo los derivados. En Ecuador se consumen alrededor de 100 litros de leche por año por habitante y deberíamos consumir por lo menos 150, para cumplir las reco- 
mendaciones alimenticias. Uruguay consume 225 litros al año por habitante.

\section{¿Han sido efectivas las cam- pañas de consumo de leche en Ecuador?}

Hemos intentado hacerlas así, pero no las hemos logrado articular bien porque son muy costosas, hasta hace 5 años nos defendíamos solos, ahora estamos solicitando al gobierno que nos ayude, y ha tenido la virtud de apoyar la producción de leche, pero tanto, que la producción ha subido de forma tan increíble que se está botando, lo que es un crimen atroz.

Entre el gobierno y el sector privado, hay que decirle a la gente que consuma leche porque le hace bien, y desmitificar el concepto de que le hace mal.
En los bares de los colegios encuentras gaseosas, bebidas llenas de colorantes, pero no encuentras leche; las industrias no han hecho popular el consumo de leche porque es más rentable producir comida chatarra. Entonces, es necesario fortalecer la imagen y la autoestima de la población a través de un adecuado plan de medios que conciencie sobre el consumo.

Nosotros vamos a sacar unos folletitos, hechos por un nutricionista, donde les decimos a los productores que aprendan a producir sus propios derivados y consumirlos.

No dar importancia a la comunicación es una de las fallas estratégicas de la organización, la gente no está recibiendo lo que queremos comunicar, se lo debe hacer desde una visión más social. 